\title{
WING-FOLDING IN THE PALEOZOIC INSECT ORDER DIAPHANOPTERODEA (PALEOPTERA), WITH A DESCRIPTION OF NEW REPRESENTATIVES OF THE FAMILY ELMOIDAE
}

\author{
By Jarmila Kukalová-Peck ${ }^{1}$ \\ Department of Geology, Carleton University, \\ Ottawa, Ontario, Canada
}

The order Diaphanopterodea is closely related to two other Paleozoic paleopterous orders, the Palaeodictyoptera and the Megasecoptera, all three having elongate, haustellate mouth-parts. In the history of the study of paleopterous insects, the Diaphanopterodea represent the most intriguing group. The order combines the basic characteristics of the Paleoptera, fluted wings and very long, multisegmented cerci, with the ability to fold the wings backwards over the abdomen, which is the principal character of the Neoptera. Since that resting position of the wings indicates a major development in the evolution of insects, as well as major achievement in adaptation to more varied environment, its occurrence within the Paleoptera is of great interest.

At present there is general agreement among students of insect evolution that wing-folding ability arose at least twice in insects in the Neoptera and in the Diaphanopterodea among the Paleoptera (Rohdendorf 1962, Carpenter 1963, Sharov 1971). It has been assumed that the wing-folding mechanism in the Diaphanopterodea was probably different from that in the Neoptera, but the structure of the axillary region of the diaphanopteran wing has not actually been known. While examining all known specimens of Diaphanopterodea from the Lower Permian deposits of Czechoslovakia, Kansas and Oklahoma, I succeeded in finding a dozen wings, belonging to the families Elmoidae, Martynoviidae and Asthenohymenidae, with the bases of the wings at least partially preserved. The present paper is concerned only with the family Elmoidae; the two remaining

\footnotetext{
${ }^{1}$ This research has been supported in part by the President's Research Grant (Canadian National Research Council) from Carleton University, and in part by NSF Grant G.B. 39720, F. M. Carpenter, Harvard University, Principal Investigator.

I am deeply indebted to Professor F. M. Carpenter for placing at my disposal the Diaphanopterodea in the Museum of Comparative Zoology which he had collected in Kansas and Oklahoma, and for his critical review of this manuscript.

Manuscript received by the editor June 20, 1974.
} 
families and the wing base morphology of the Palaeodictyoptera and Megasecoptera will be discussed elsewhere.

The new material includes six new genera and ten new species of Elmoidae from the Lower Permian beds near Obora in Moravia, Czechoslovakia. The base of the wing is well preserved in one specimen only, Permodiapha carpenteri n.sp. (No. 8/1974), and incompletely preserved in seven other specimens.

Since no definitive studies of the wing bases of the extant Paleoptera [Odonata and Ephemeroptera] have been made, some difference of opinion exists about the interpretation of the basal sclerites. The interpretation of the diaphanopteran structures used in this paper should be considered only as tentative. The terminology employed is derived from the account of the wing base of Odonata by Tannert (1958), since the fore wing base in the Ephemeroptera has never been described in functional terms. For further comparison, the wing base structures of the related family Martynoviidae (undescribed material) and the related order Palaeodictyoptera (Kukalová 1960, 1969, 1970) have been used.

\section{Family Elmoidae}

Elmoidae Tillyard 1937: 82; Carpenter 1943: 56; Carpenter 1947: 27;

Rohdendorf 1962: 69; Carpenter 1963: 249.

Parelmoidae Rohdendorf 1962: 71.

The family Elmoidae was originally assigned by Tillyard to the paleopterous order Megasecoptera because of the similarity in the venation pattern. This point of view was followed by Carpenter in his emendation of Elmoidae in 1943 and 1947, although he subsequently (1954) separated the Elmoidae, along with the Diaphanopteridae and related families, into a distinct suborder (Paramegasecoptera), on the basis of the folded, resting position of the wings. Later, Rohdendorf (I962) and Carpenter (1963) independently reached the conclusion that these families had to be referred to the separate order Diaphanopterodea, established by Handlirsch (1919). A detailed evaluation of the phylogenetic position of Elmoidae and Diaphanopteridae within the order, and of Diaphanopterodea within the Paleoptera has been given by Carpenter (1963).

Until now, the family has been known by only three genera, all from the Lower Permian of Kansas and Oklahoma-Elmoa, Parelmoa, and Pseudelmoa, represented by five species. The new fossils from Moravia contribute additional and varied morphological features, which broaden the family characteristics formerly used. In the Moravian material thickened cuticular spots are sometimes pres- 

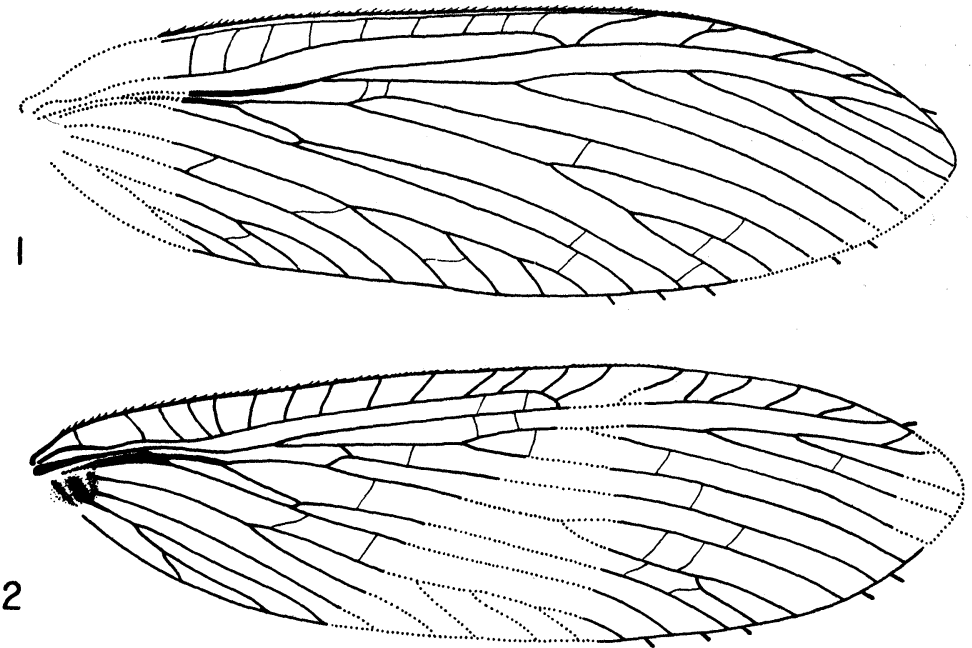

3

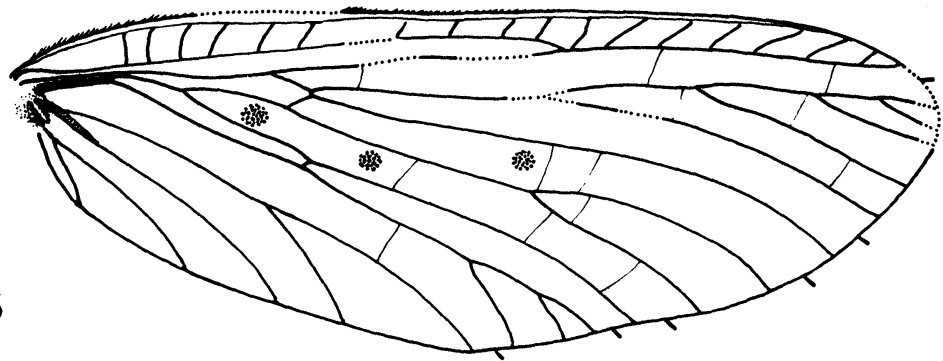

4

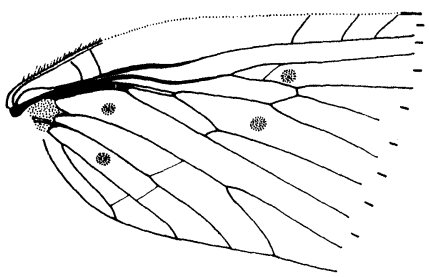

Fig. 1. Elmodiapha ovata n.sp., specimen $1 / 1974$, fore wing. Holotype. Fig. 2. Elmodiapha ovata n.sp., specimen $2 / 1974$, fore wing. Fig. 3. Protodiapha maculifera n.sp., specimen $3 / 1974$, hind wing. Holotype. Fig. 4. Protodiapha maculifera n.sp., specimen 4/1974, hind wing. 
ent on the wings, between the veins, and the main veins are covered with a series of setae. Costa is flattened and in larger wings sometimes serrated; it often carries a series of long setae, which are more pronounced basally. Subcosta consistently forms a conspicuous bend at the very base, probably related to the wing-folding process. Radius is always fused basally with the stem of the media. M, after diverging from $\mathrm{R}$, immediately coalesces or joins either the stem of $\mathrm{Cu}$ and $\mathrm{CuA}$, or directly $\mathrm{CuA}$, for a short distance. $\mathrm{MA}$ and Rs are connected in North American Elmoidae by a cross vein. In Moravian Elmoidae the cross vein is present in only three species. In others, MA almost touches Rs or MA joins Rs at a point, or for a short distance, or both veins are anastomosed for a short distance. Cubitus runs closely to, or touches, $\mathrm{R}$. The stem of $\mathrm{Cu}$ is always ribbon-like, deeply concave, broad and flattened. $\mathrm{CuA}$ and $\mathrm{CuP}$ originate near the point at which $M$ diverges from the common $R+M$ stem. Soon after diverging from $\mathrm{M}, \mathrm{CuA}$ approaches $\mathrm{CuP}$ and is connected with it by an oblique cross vein. This feature seems to be a stable character of the family. Anal veins start from the posterior part of the sclerotized region, which is the thickened part of the wing membrane posteriorly from $\mathrm{Cu}$ and distally from the basal fold (fig. IO,S). It undoubtedly served as a reinforcement of the wing base while folding the wings backwards. The basal plate is represented either by the enlarged cubitoanal plate, or by the fusion of the median, cubital, and anal plates. It is partly homologous with the fused subcostoanal plate of the Palaeodictyoptera, the fused basal plate of the Ephemeroptera, and the radioanal plate of the Odonata. The basal fold runs between $S c$ and $R+M$, crosses $R+M$ where it is flattened and weakly sclerotized, follows closely the distal margin of the fused basal plate, and crosses the anal part of the sclerotized region (fig. IO,B). The axillary sclerite articulates with the proximal margin of the basal plate and with $\mathrm{R}$. Its size and shape are not known.

The family Elmoidae, as long as it was known only by North American species, was well separated from the related Upper Carboniferous family Diaphanopteridae. The family Diaphanopteridae, represented by Diaphanoptera (France) and Philiasptilon (Soviet Union, Kuznetsk Basin), was characterized by the presence of the anastomosis between MA and Rs. In the Permian material from Moravia, however, this feature is highly variable. In Elmodiapha and Protodiapha (new genera), MA and Rs are connected only by a cross vein, as in the Elmoidae from Kansas and Oklahoma. In the other Moravian genera, MA and Rs are either touching each other 

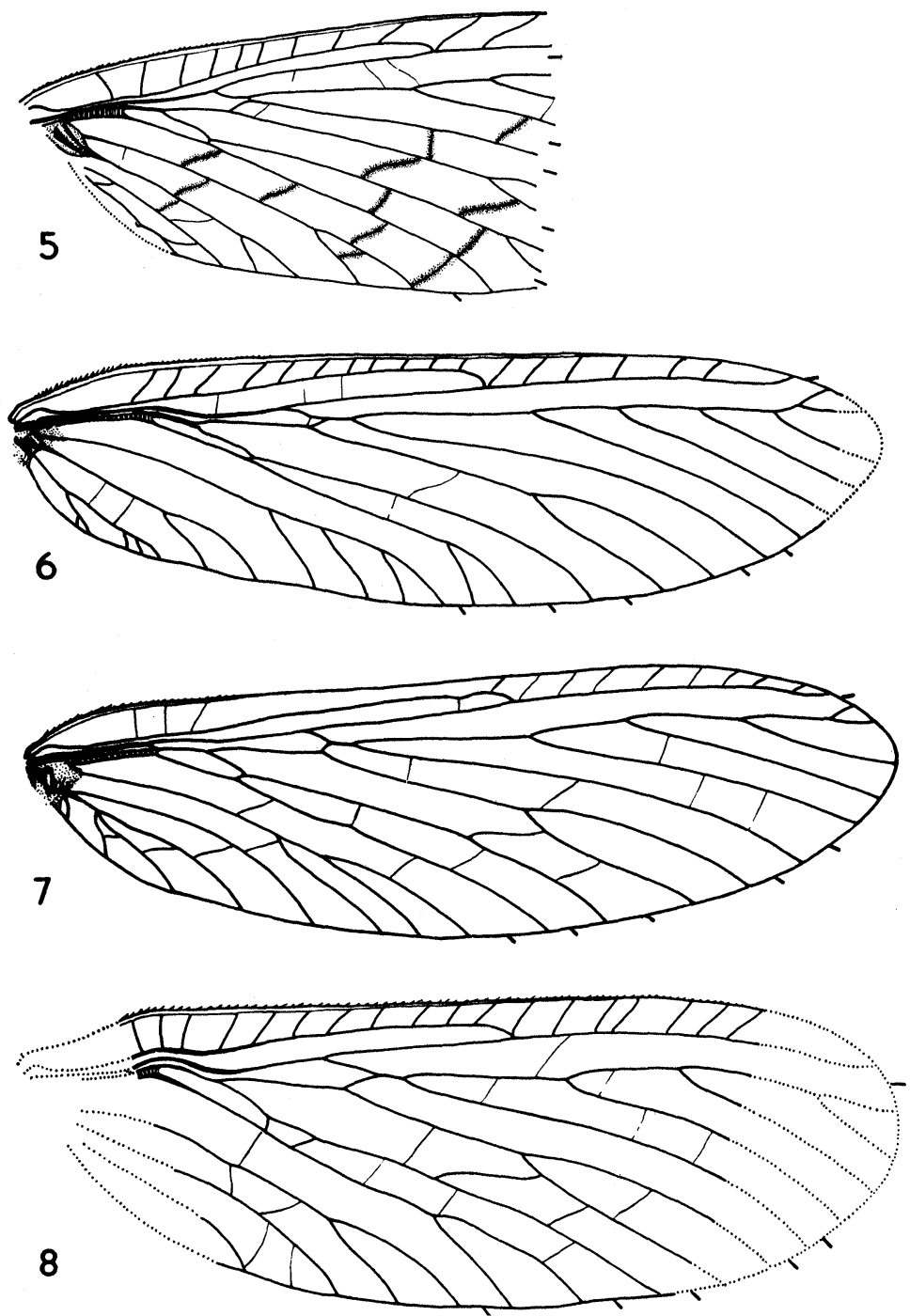

Fig. 5. Protodiapha lineata n.sp., specimen $5 / 1974$, fore wing. Holotype. Fig. 6. Diapha candida n.sp., specimen $6 / 1974$, fore wing. Holotype. Fig. 7. Diapha candida n.sp., specimen $7 / 1974$, hind wing. Fig. 8. Permodiapha carpenteri n.sp., specimen 11/1974, fore wing. 
at a point, or anastomosed as in Diaphanopteridae. Since the presence or absence of the MA-Rs anastomosis is no longer useful as the family character, the status of the Elmoidae as a separate family is questionable. However, since Diaphanoptera, the type genus of the family, is from Upper Carboniferous strata, and since its body structure is entirely unknown, it seems advisable to consider the families distinct at least until more is known about Diaphanoptera.

The generic classification used here is based mainly upon the presence or absence of MA-Rs anastomosis, the general shape of the wings, and the character of the Rs area, since these features have been found relatively stable in the related order Palaeodictyoptera (Kukalová-Peck, I97I). All specimens available are figured. The lettering of the veins is shown in figures 9 and ro.

\section{Genus Elmodiapha, new genus ${ }^{2}$}

Type species: Elmodiapha ovata n.sp., Lower Permian of Moravia.

Fore wing: MA and Rs not anastomosed, connected by a cross vein. Wings elongated, oval in shape. Sc terminating on $R$ shortly beyond mid-wing. Rs area large, with about 6 branches. $R$ sending off a series of long branches beyond the end of Sc. Hind wing not known.

Elmodiapha differs from Parelmoa in having more elongate wings and richly branched Rs. From Pseudelmoa it differs in the shorter $\mathrm{Sc}$, and in MA approaching more closely to Rs.

\section{Elmodiapha ovata n.sp.}

Figure I, 2

This species is represented by two detached fore wings with a richly branched Rs.

Fore wing: length $17.5-21 \mathrm{~mm}$, width $5.4-6.6 \mathrm{~mm}$. Costa serrated. Rs with 6 long, densely arranged branches. MA simple, MP twice forked. $\mathrm{CuA}$ and $\mathrm{CuP}$ simple. IA usually with a series of branches, anal veins sometimes branched.

Holotype: No. I/1974 (fore wing fragment, length $18.5 \mathrm{~mm}$, width $6.6 \mathrm{~mm}$, obverse); specimen No. 2/1974 (fore wing fragment, length $16 \mathrm{~mm}$, width $5.4 \mathrm{~mm}$, obverse and reverse). Paleontological Institute of Charles University, Prague, Czechoslovakia.

\footnotetext{
${ }^{2}$ The latter part of this generic name (and that of the other genera which are proposed in this paper) is derived from the Greek adjective diaphanes (distinct); it is treated as a noun and is considered feminine
} 
Genus Protodiapha, new genus

Type species: Protodiapha maculifera n.sp., Lower Permian of Moravia.

Fore wing: MA and Rs connected with a very short cross vein. Wings short and broad, broadest at about mid-wing. Posterior margin convexly bent, forming a lobe. Sc terminating on $\mathrm{R}$ shortly beyond mid-wing. Rs area small, with about 5 branches. Hind wing similar, but shorter, with the lobe on the posterior margin probably more pronounced.

Protodiapha differs from all the other genera which lack the anastomosis between MA and Rs by the presence of the lobe on the posterior margin.

\section{Protodiapha maculifera n.sp.}

Figure 3, 4

This species is established upon hind wings having a prominent lobe on the posterior margin and circular, cuticular spots on the wing membrane.

Hind wing: length $14 \mathrm{~mm}$, width $4.5-5 \mathrm{~mm}$. Wing broadest before the level of the end of Sc. The lobe on the posterior margin extending to the end of $\mathrm{CuP}$. C with a series of long setae. Rs almost straight, with 5 branches. MA simple, MP with a fork. $\mathrm{CuA}$ simple, $\mathrm{CuP}$ sometimes with short branches. Anal veins with few branches. Thickened cuticular spots present.

Holotype: No. 3/1974 (hind wing, length $13.5 \mathrm{~mm}$, width 4.5 $\mathrm{mm}$, obverse) ; specimen No. 4/1974 (hind wing fragment, length $8.3 \mathrm{~mm}$, width $5 \mathrm{~mm}$, obverse). Paleontological Institute of Charles University, Prague, Czechoslovakia.

\section{Protodiapha lineata n.sp.}

Figure 5

This species is monotypic and based on the proximal half of a fore wing. However, the unique S-shaped cross veins accompanied by dark spots separate the species distinctly from all other Elmoidae.

Fore wing: length of the fragment II.4 mm, width $5.8 \mathrm{~mm}$. Wing broadest beyond the level of the end of Sc. The small lobe on the posterior margin extending to the end of CuP. Veins darkly colored. $\mathrm{CuA}$ with a short branch, $\mathrm{CuP}$ simple. Anal veins with few branches. Cross veins long, S-shaped, surrounded by dark spots. Circular cuticular spots absent. 

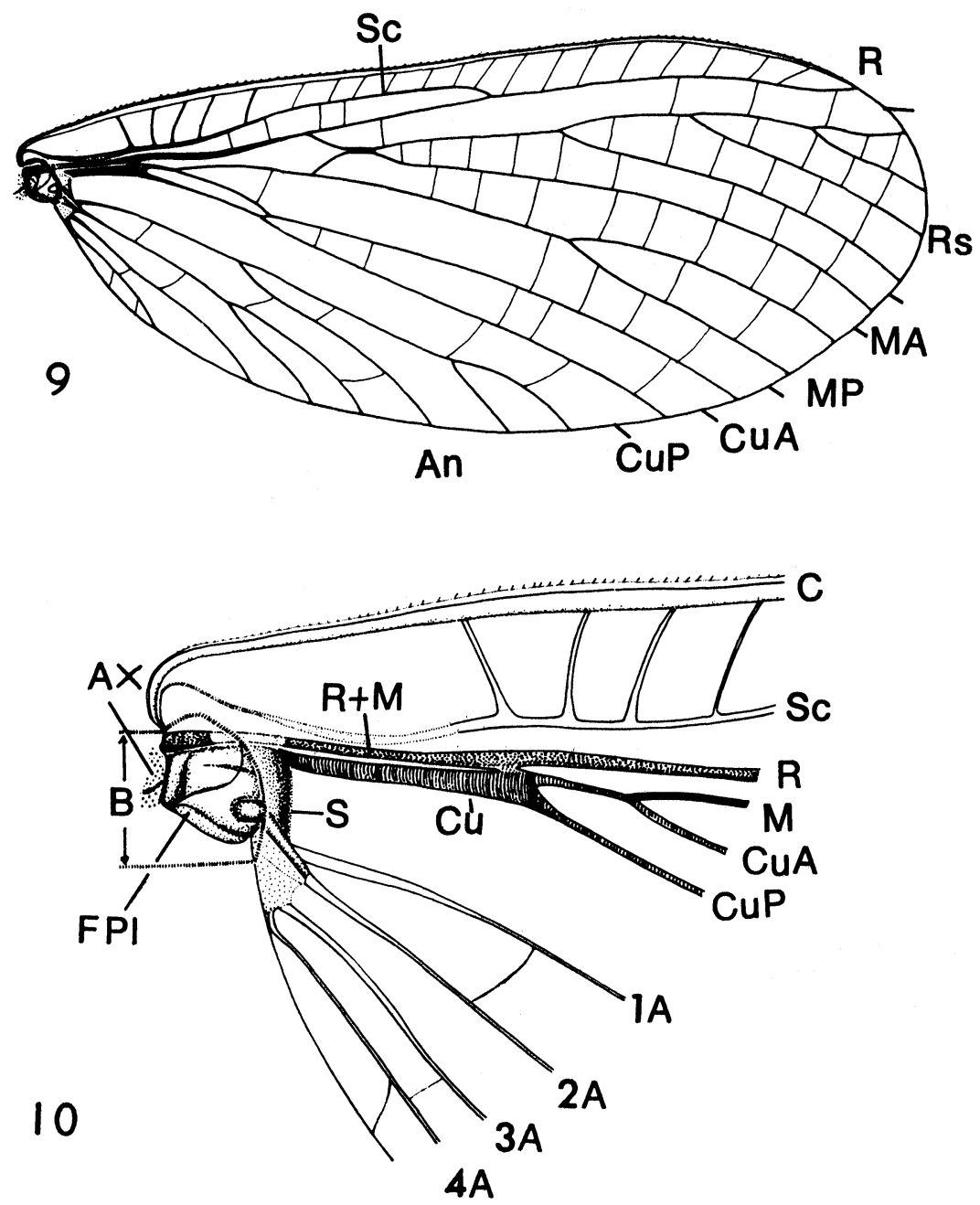

Fig. 9. Permodiapha carpenteri n.sp., specimen $8 / 1974$, hind wing. Holotype. Fig. 10. Permodiapha carpenteri n.sp., specimen $8 / 1974$, hind wing. Holotype. Ax $=$ axillary sclerite; $B=$ basal fold ; $\mathrm{FPl}=$ fused basal plate; $\mathrm{S}=$ sclerotized region. 
Protodiapha lineata differs from maculifera in having the wings widest beyond mid-wing, a smaller lobe on the posterior margin and long, S-shaped cross veins.

Holotype: No. 5/1974 (fore wing fragment, length II.4 mm, width $5.8 \mathrm{~mm}$, obverse). Paleontological Institute of Charles University, Prague, Czechoslovakia).

\section{Genus Diapha, new genus}

Type species: Diapha candida n.sp., Lower Permian of Moravia.

Fore wing: $\mathrm{MA}$ anastomosing with $\mathrm{Rs}$ for a short distance. Wings slightly broadened beyond mid-wing. Posterior margin concave. Sc terminating on $\mathrm{R}$ shortly beyond mid-wing. Rs with 5-6 branches. Hind wing shorter and probably narrower, with anal veins less branched. Diapha differs from the other genera described herein by the shape of the wings.

\section{Diapha candida n.sp.}

Figure 6, 7

A detached fore wing and a hind wing are referred to this species. The hind wing differs slightly in the outline of the posterior margin and in the thinner membrane. It may belong to a different 'species.

Fore wing: length $19 \mathrm{~mm}$, width $5 \mathrm{~mm}$. Wing broader in the distal half. $\mathrm{C}$ basally with a series of more prominent setae. Stem of $\mathrm{R}$ distinctly swollen next and distally from the basal fold. Rs concavely bent in the apical part, with 6 branches. MA simple, MP forked. $\mathrm{CuA}$ simple, $\mathrm{CuP}$ simple or with a branch. IA with several branches, anal veins sometimes branched.

Hind wing: length $14 \mathrm{~mm}$, with $4.2 \mathrm{~mm}$. Wing membrane very thin.

Holotype: No. 6/1974 (fore wing, length $18.7 \mathrm{~mm}$, width $5 \mathrm{~mm}$, obverse); specimen No. 7/1974 (hind wing, length $14 \mathrm{~mm}$, width $4.2 \mathrm{~mm}$, obverse and reverse). Paleontological Institute of Charles University, Prague, Czechoslovakia.

\section{Genus Permodiapha, new genus}

Type species: Permodiapha carpenteri n.sp., Lower Permian of Moravia.

Fore wing: MA touching Rs or anastomosing with Rs for a short distance. Wing very broad. Posterior margin evenly concave. Sc terminating on $\mathrm{R}$ shortly beyond mid-wing. Rs with 3-4 branches. Hind wing similar to fore wing, but broader. 

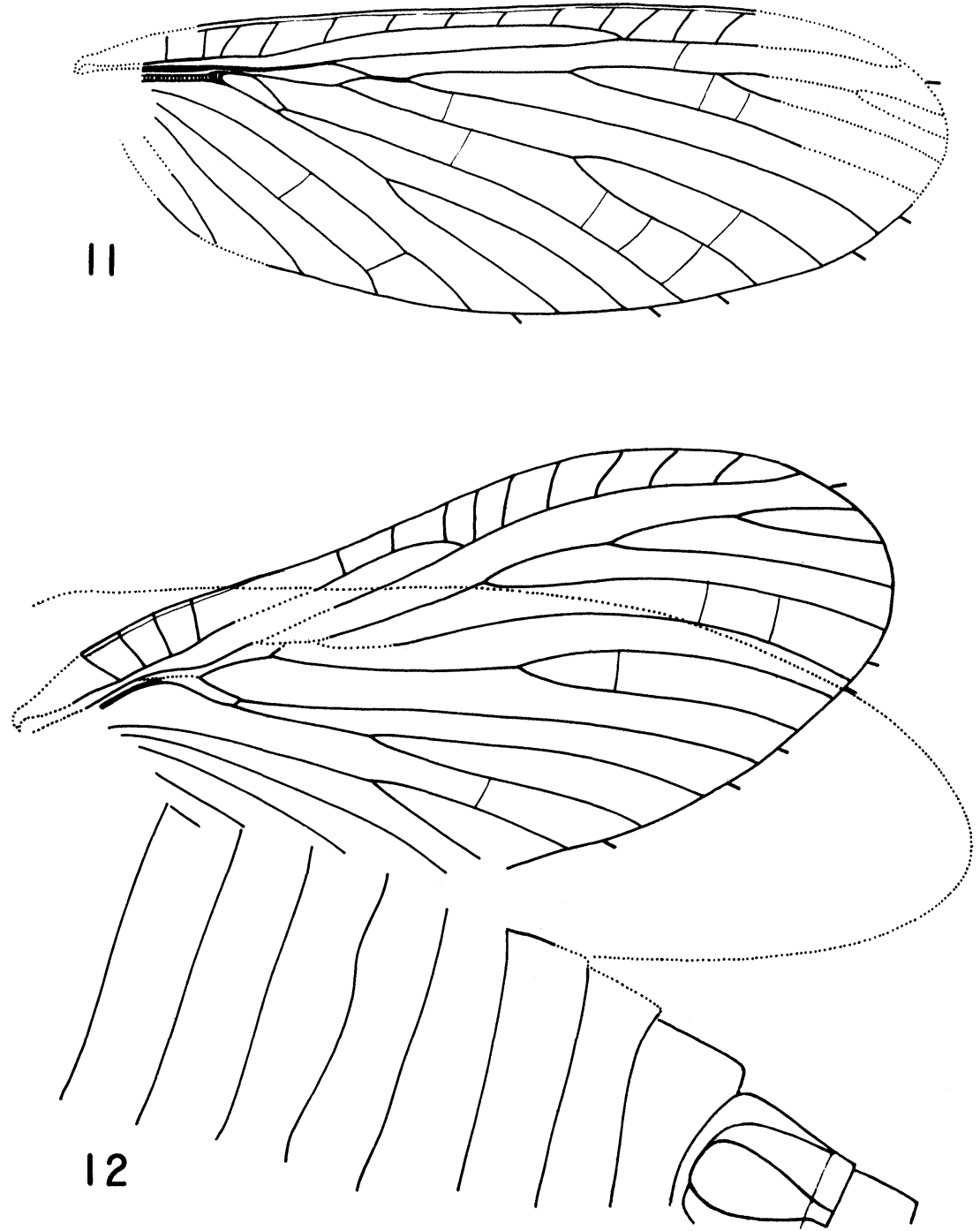

Fig. 11. Permodiapha lata n.sp., specimen 10/1974, fore wing. Fig. 12. Permodiapha lata n.sp., specimen 9/1974. Hind wing, fore wing outlined. Holotype. 
Permodiapha differs from all other genera with MA-Rs anastomosed by its very broad wings.

\section{Permodiapha carpenteri n.sp. ${ }^{3}$}

Figure 8, 9, I0

A detached fore wing and a hind wing are referred to this species. The hind wing No. 8/1974 has been chosen as the holotype because of its well preserved base. The structure of the wing base are discussed above with the family characters.

Fore wing: length about $16 \mathrm{~mm}$, width $5.3 \mathrm{~mm}$. Wing large, with relatively strong membrane, veins and cross veins. Apex probably rounded as in the hind wing. Rs sending off 4 branches, slightly S-shaped distally. MA simple, MP with a long fork. $\mathrm{CuA}$ simple, $\mathrm{CuP}$ simple or forked. Anal veins with several branches. Fore wing about equally long but narrower than the hind wing.

Hind wing: length $16.3 \mathrm{~mm}$, width $6.8 \mathrm{~mm}$. Similar to the fore wing but broader, and narrowing more towards the base.

Holotype: No. 8/1974 (hind wing, length $16.3 \mathrm{~mm}$, width 6.8 $\mathrm{mm}$, obverse and reverse); specimen No. I I/I974 (fore wing fragment, length II mm, width $5.3 \mathrm{~mm}$, reverse). Paleontological Institute of Charles University, Prague, Czechoslovakia.

\section{Permodiapha lata n.sp.}

Figure II, I2

The species is represented by the holotype, probably a male, consisting of a vaguely preserved fore wing, well preserved hind wing and part of the abdomen, and by a detached wing, probably a fore wing.

Fore wing: length about $12.6-15.5 \mathrm{~mm}$, width $4.9-5.2 \mathrm{~mm}$. Wing membrane very delicate, cross veins almost invisible. Apical part of the wing somewhat narrower than in carpenteri. Rs curved posteriorly, sending off 4 branches. MA and CuA simple, MP and $\mathrm{CuP}$ with a long fork. Anal veins with few branches. Fore wing longer and narrower, with the apical part more pointed than the hind wing. Hind wing: length about $14.5 \mathrm{~mm}$, width $6 \mathrm{~mm}$. Anterior margin strongly curved towards the apex.

Permodiapha lata differs from carpenteri in having a very thin membrane and narrower fore wings.

\footnotetext{
${ }^{3}$ This species is named for Dr. Frank M. Carpenter (Harvard University), who has published extensively on the Diaphanopterodea.
} 


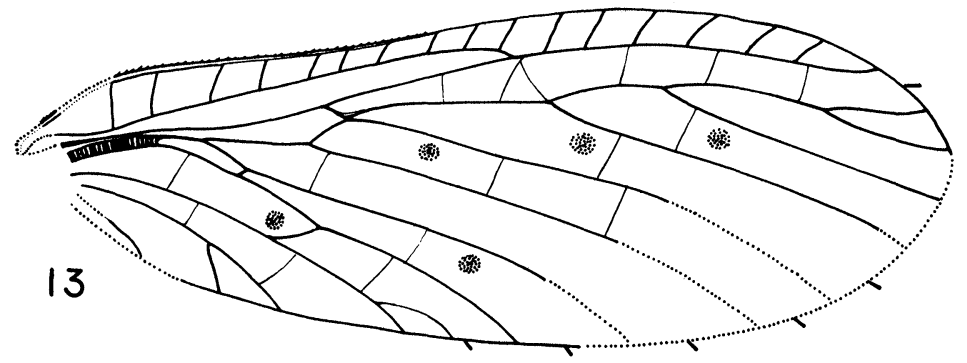

14
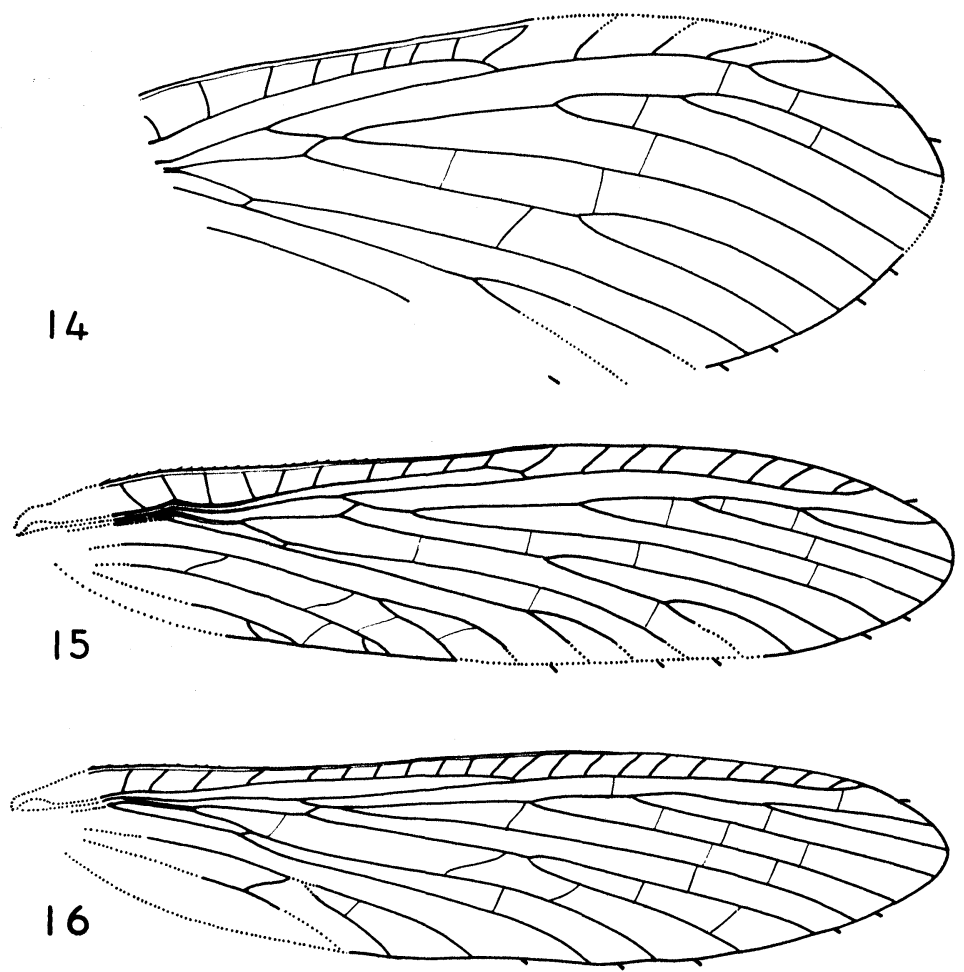

Fig. 13. Permodiapha specula n.sp., specimen 13/1974, fore wing. Holotype. Fig. 14. Permodiapha sp., specimen 14/1974, hind wing. Fig. 15. Stenodiapha angusta n.sp., specimen 17/1974, fore wing. Holotype. Fig. 16. Stenodiapha angusta n.sp., specimen 18/1974, fore wing. 
Holotype: No. 9/1974 (fore wing, length about $15.5 \mathrm{~mm}$, width $5.2 \mathrm{~mm}$; hind wing fragment, length $13 \mathrm{~mm}$, width $6 \mathrm{~mm}$; abdomen, I.-IO. segment, length I $3.5 \mathrm{~mm}$; hind tibia, length $3 \mathrm{~mm}$; obverse); specimen No. IO/1974 (fore wing fragment, length $12.6 \mathrm{~mm}$, width $4.9 \mathrm{~mm}$, obverse). Paleontological Institute of Charles University, Prague, Czechoslovakia.

\section{Permodiapha specula n.sp.}

Figure 13

This species is monotypic and based upon a fore wing.

Fore wing: length $13.3 \mathrm{~mm}$, width $4.8 \mathrm{~mm}$. Wing relatively small, with very thin wing membrane. Cross veins almost invisible. Proximal half of the wing much narrower than the distal half. Venation very simple, seldomly branched. MA only touching Rs at a point. Rs sending off 4 branches, Rs S-shaped distally. MA, $\mathrm{MP}, \mathrm{CuA}$ and $\mathrm{CuP}$ simple. Anal veins mostly simple. Circular cuticular spots present.

Permodiapha specula differs from carpenteri and lata in having the smallest wings with the most simple venation; in having the wings narrowed in the proximal half; and in the presence of the circular cuticular spots.

Holotype: No. 13/1974 (fore wing, length $13.3 \mathrm{~mm}$, width 4.8 $\mathrm{mm}$, obverse and reverse). Paleontological Institute of Charles University, Czechoslovakia.

Permodiapha sp. specimen No. 14/1974 (fig. I4) (hind wing fragment, length II $\mathrm{mm}$, width $4.5 \mathrm{~mm}$, obverse and reverse) might represent a separate species within the genus Permodiapha, but the fragment does not provide enough features for specific diagnosis.

\section{Genus Stenodiapha, new genus}

Type species: Stenodiapha angusta n.sp., Lower Permian of Moravia.

Fore wing: MA anastomosed with $\mathrm{Rs}$ for a short distance. Wing narrow, elongate, with main veins obliquely oriented. Sc terminating on $\mathrm{R}$ shortly beyond mid-wing. Rs with 3-4 branches, rs area long and narrow. Hind wing similar to the fore wing, but shorter and broader.

Stenodiapha differs from all other genera with MA-Rs anastomosed by the longest and narrowest wings, with the veins most obliquely oriented. 

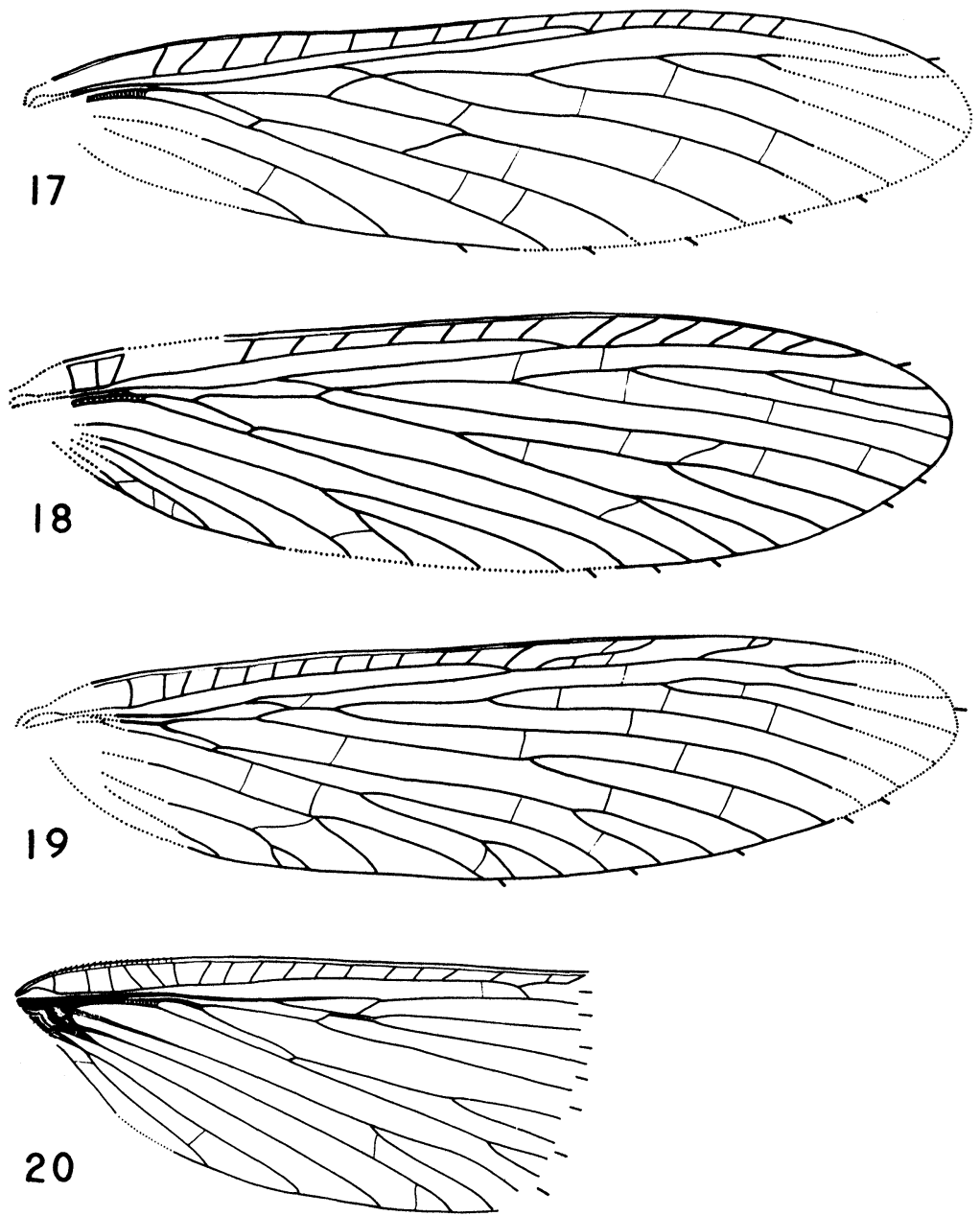

Fig. 17. Stenodiapha angusta n.sp., specimen 19/1974, fore wing. Fig. 18. Stenodiapha angusta n.sp., specimen 20/1974, hind wing. Fig. 19. Stenodiapha moravica n.sp., specimen 21/1974, fore wing. Holotype. Fig. 20. Stenodiapha moravica n.sp., specimen $22 / 1974$, fore wing. 


\section{Stenodiapha angusta n.sp.}

Figures I5, I6, I7, I8

Three detached fore wings and one hind wing are referred to this species.

Fore wing: length $\mathrm{I} 7.2-20 \mathrm{~mm}$, width $3.8-4.3 \mathrm{~mm}$. Wing broadest at mid-wing, narrowing proximally. Wing membrane very thin. Rs with 4 long branches. MA simple, MP simple; $\mathrm{CuA}$ simple, $\mathrm{CuP}$ simple or forked. Anal veins with few branches or simple. Hind wing: length about $16.5 \mathrm{~mm}$, width $4.4 \mathrm{~mm}$. Similar to the fore wing, but shorter. In hind wing No. 20/1974, the richly branched MP is reminiscent of the Carboniferous genus Diaphanoptera.

Holotype: No. I7/I974 (fore wing fragment, length $18.2 \mathrm{~mm}$, width $4.3 \mathrm{~mm}$, obverse); specimen No. $18 / 1974$ (fore wing fragment, length $15.7 \mathrm{~mm}$, width $3.8 \mathrm{~mm}$, obverse and reverse) ; specimen No. 19/1974 (fore wing fragment, length $14.6 \mathrm{~mm}$, width $3.8 \mathrm{~mm}$, obverse and reverse) ; specimen No. 20/1974 (hind wing fragment, length I $5 \mathrm{~mm}$, width $4.4 \mathrm{~mm}$, obverse and reverse). Paleontological Institute of Charles University, Prague, Czechoslovakia.

\section{Stenodiapha moravica n.sp.}

Figure 19, 20

This species is based on two detached wings, probably fore wings.

Fore wing: length about $20.7 \mathrm{~mm}$, width $5.3 \mathrm{~mm}$. Wing broadened slightly at mid-wing. $\mathrm{C}$ serrated, basally carrying a series of setae. $\mathrm{R}$ sending off anteriorly several long twigs beyond the end of Sc. Rs with 3 long branches. MA simple, MP forked. CuA and $\mathrm{CuP}$ forked. Anal veins with few branches or simple.

Stenodiapha moravica differs from angusta in having the wings broader in the basal third and in the presence of long twigs on $\mathrm{R}$ beyond the end of Sc.

Holotype: No. 2I/1974 (fore wing fragment, length $19.2 \mathrm{~mm}$, width $5.3 \mathrm{~mm}$, obverse and reverse); specimen No. 22/1974 (fore wing fragment, length II $.5 \mathrm{~mm}$, width $5.3 \mathrm{~mm}$, obverse). Paleontological Institute of Charles University, Prague, Czechoslovakia.

Paradiapha, new genus

Type species: Paradiapha delicatula n.sp., Lower Permian of Moravia.

Fore wing: MA joining Rs for a short distance. Wing broadest at about the end of the second third, narrowing abruptly at the base. $\mathrm{C}$ serrated. Sc terminating on $\mathrm{R}$ shortly beyond mid-wing. 

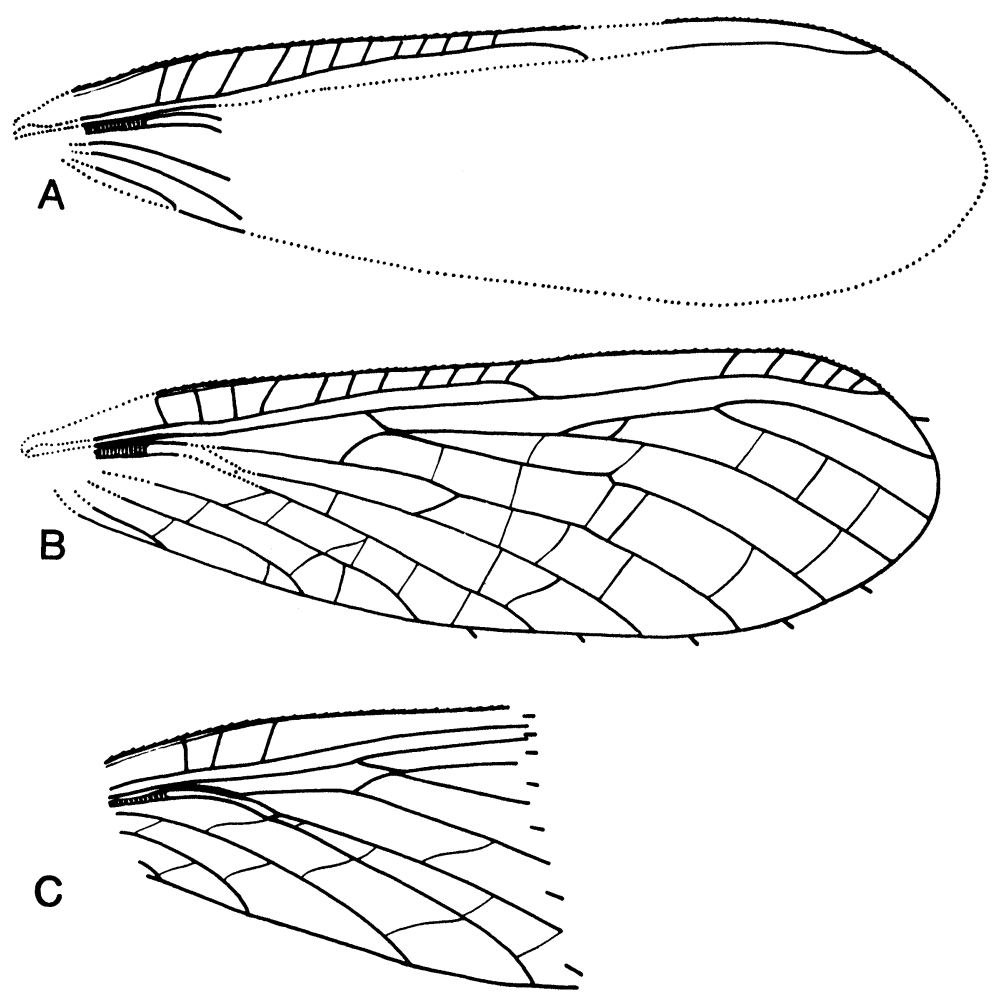

Fig. 21. Paradiapha delicatula n.sp., specimen 15/1974. Holotype. A. right fore wing, B. left hind wing, C. right hind wing. 
Rs area small, with about 3 Rs branches. Hind wing similar to the fore wing, slightly shorter and broader proximally.

Paradiapha has a similar wing shape to Parelmoa, from which it differs in having a shorter Sc and by having MA almost anastomosed with Rs. From all other genera it differs in the wings being very broad in the distal third.

\section{Paradiapha delicatula n.sp.}

Figure 21, 22

The species is based upon two specimens. The holotype consists of the fragment of the right fore wing, of an almost complete left hind wing, and of the basal third of the right hind wing, all in partly folded position. Specimen No. 16/1974 is represented by the fragments of overlapping fore and hind wings, broad pterothorax and a remnant of the hind leg, with prominent setae on the tibia.

Fore wing: length about $12.9 \mathrm{~mm}$, width about $4.3 \mathrm{~mm}$. Wing membrane very thin. Anterior margin strongly bent apically, apex shifted posteriorly. C serrated, with a series of long setae. Rs strongly curved posteriorly, sending off 3 branches. MA, MP, CuA, $\mathrm{CuP}$ and anal veins simple. Hind wing almost identical with the fore wing, slightly shorter.

Holotype: No. 15/1974 (right fore wing fragment, length I2.6 $\mathrm{mm}$; left hind wing fragment, length $12.8 \mathrm{~mm}$, width $4.3 \mathrm{~mm}$; right hind wing fragment, length $7.4 \mathrm{~mm}$, width $4 \mathrm{~mm}$; reverse); specimen No. I6/1974 (fore wing fragment, length $8.7 \mathrm{~mm}$; hind wing fragment, length $6.2 \mathrm{~mm}$; hind tibia, length $1.8 \mathrm{~mm}$; obverse). Paleontological Institute of Charles University, Prague, Czechoslovakia.

\section{Discussion}

On superficial examination, the wing base in Permodiapha does not differ from the generalized neopterous type. The axillary region penetrates deeply into the wing, from which it is separated by the basal fold. However, careful study reveals that instead of the second and third axillary sclerites, which would be located proximally from the basal fold in true Neoptera, there is a large basal plate which is characteristic of the Paleoptera. The true axillary sclerite (fig. $9, \mathrm{Ax}$ ), perhaps homologous with $2 \mathrm{Ax}$ in Ephemeroptera (sensu Tsui and Peters, 1972), is located much more distally, in the "paleopterous" position. 


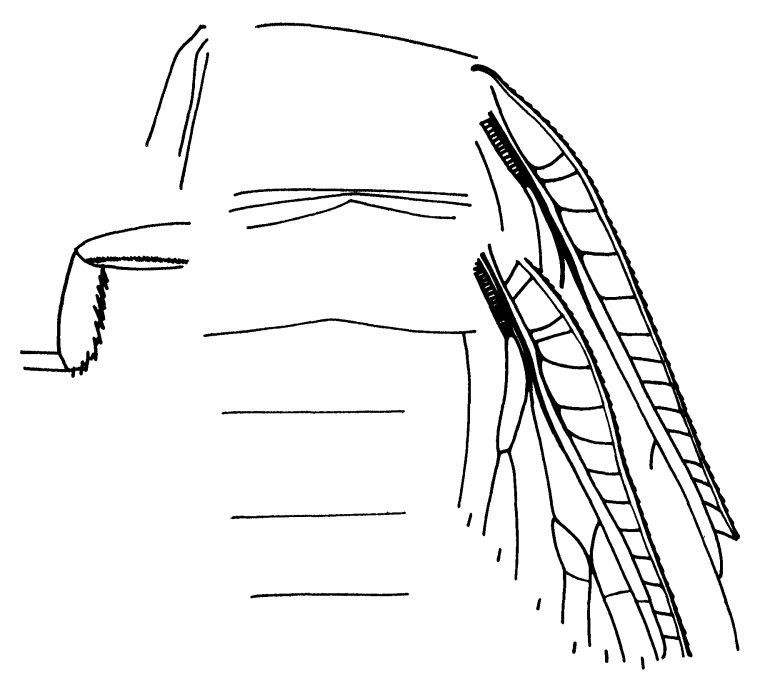

Fig. 22. Paradiapha delicatula n.sp., specimen 16/1974. Fore wing and hind wing, hind leg.

With the subcostoanal basal plate of advanced Palaeodictyoptera (Kukalová, 1970), the basal plate of Diaphanopterodea is only partially homologous. It is apparently formed only by the fused cubitoanal plate or eventually by the mediocubitoanal plate in which subcostal and radial basal plates do not participate. This condition is reminiscent of the "prefusion" stage of basal plates, known in primitive Palaeodictyoptera (Kukalová, I960), from which Diaphanopterodea are supposedly derived.

The diaphanopteran wing base developed, in all probability, from the ancient paleopterous base, at the stage when the basal plates of the main veins were still separated, as indicated in some ancient Palaeodictyoptera. While the subcostal and radial plate became completely reduced to give place to the basal fold, the cubital and anal (or median, cubital, and anal) plates gradually fused and became separated from the wing by the basal fold.

The ability to penetrate narrow spaces for feeding and protection was undoubtedly a major factor in the success of Neoptera. The Diaphanopterodea, although having a wing-folding mechanism of their own, had highly specialized, haustellate mouthparts, as did their relatives, the Palaeodictyoptera and Megasecoptera. None of these paleopterous orders were apparently able to compete success- 
fully with the more diversified Neoptera and none have been found so far in strata formed after the close of the Permian Period.

\section{REFERENCES}

Carpenter, F. M.

1943. The Lower Permian Insects of Kansas. Part 9. The Orders Neuroptera, Raphidiodea, Caloneurodea and Protorthoptera (Probnisidae), with additional Protodonata and Megasecoptera. Proc. Amer. Acad. Arts Sci., 75(2) : 55-84.

1947. Lower Permian Insects from Oklahoma. Part 1. Introduction and the Orders Megasecoptera, Protodonata, and Odonata. Proc. Amer. Acad. Arts Sci., $76(2)$ : 25-54.

1954. Extinct Families of Insects. In Classification of Insects (C. T. Brues, A. L. Melander and F. M. Carpenter). Part III. Bull. Mus. Comp. Zool., 108 : 777-824

1963. Studies on Carboniferous Insects from Commentry, France. Part V. The Genus Diaphanoptera and the Order Diaphanopterodea. Psyche, $70(4): 240-256$.

Handlirsch, A.

1906. Die fossilen Insekten und die Phylogenie der rezenten Formen. Leipzig. $430 \mathrm{pp}$.

1919. Revision der palaeozoischen Insekten. Denkschr. Akad. Wiss. Wien. Math. Naturw. K1., 96: 82 pp.

KUKALOVÁ, J.

1960. New Palaeodictyoptera of the Carboniferous and Permian of Czechoslovakia. Sbornik UUG, 25: 236-251.

1969. Revisional Study of the Order Palaeodictyoptera in the Upper Carboniferous Shales of Commentry, France. Part 1. Psyche, 76(2) : 163-215; Part 2. Psyche, 76(4) : 439-486; Part 3. Psyche, $77(1): 1970: 1-44$.

KuKalová-PeCK, J.

1971. The Structure of Dunbaria (Palaeodictyoptera). Psyche, $78(4)$ : 306-318.

ROHDENDORF, B. B., et al.

1962. Principles of Paleontology. Akad. Nauk SSSR, Moscow. 535 pp.

TANNERT, W.

1958. Die Fluegelgelenkung bei Odonaten. Deutsche Ent. Zeit., (N.F.), $5(5): 394-455$.

Tillyard, R. J.

1937. Kansas Permian Insects. Part 17. The Order Megasecoptera and Additions to the Palaeodictyoptera, Odonata, Protoperlaria, Copeognatha, and Neuroptera. Amer. J. Sci., (5) 33 : 81-110. 

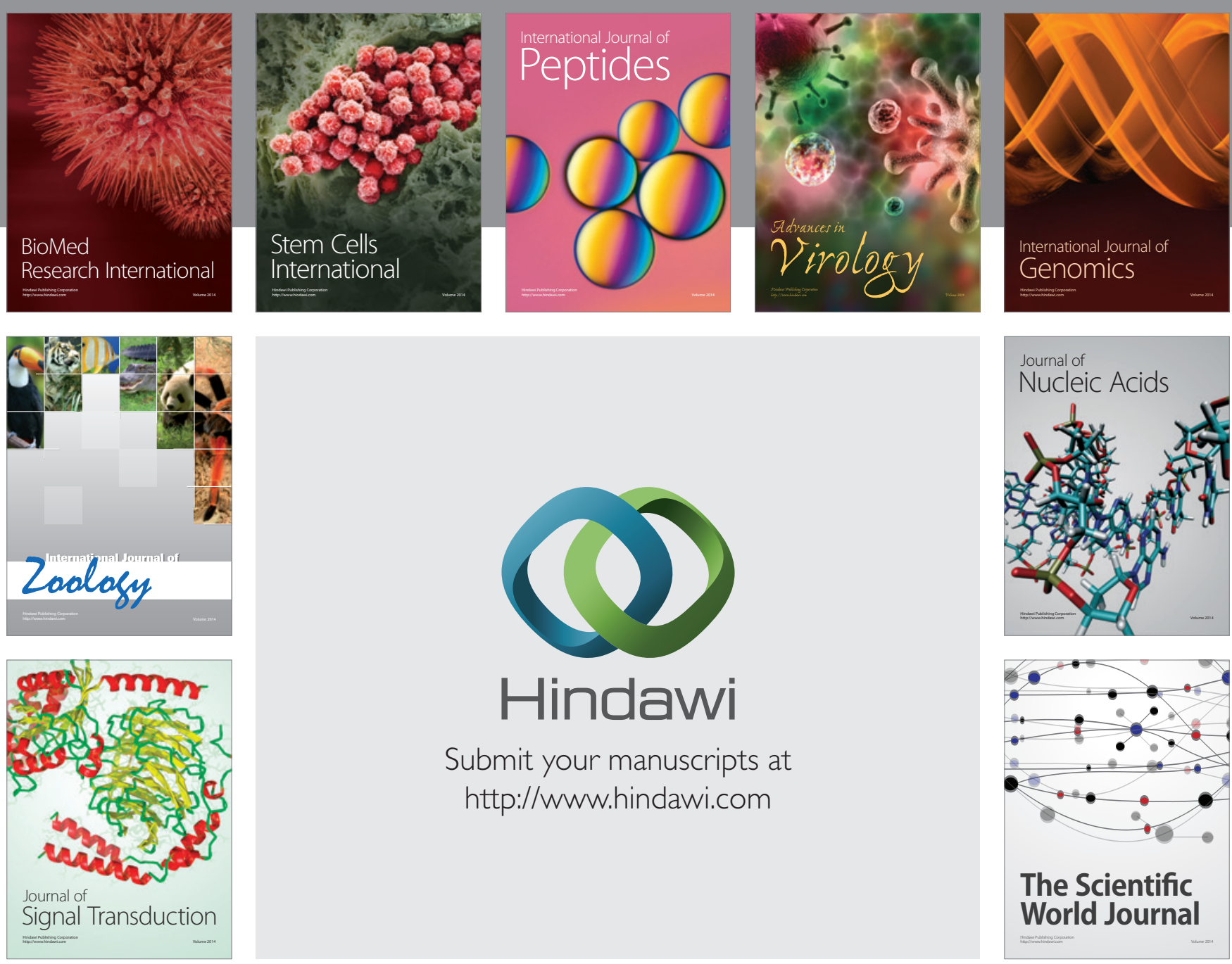

Submit your manuscripts at

http://www.hindawi.com
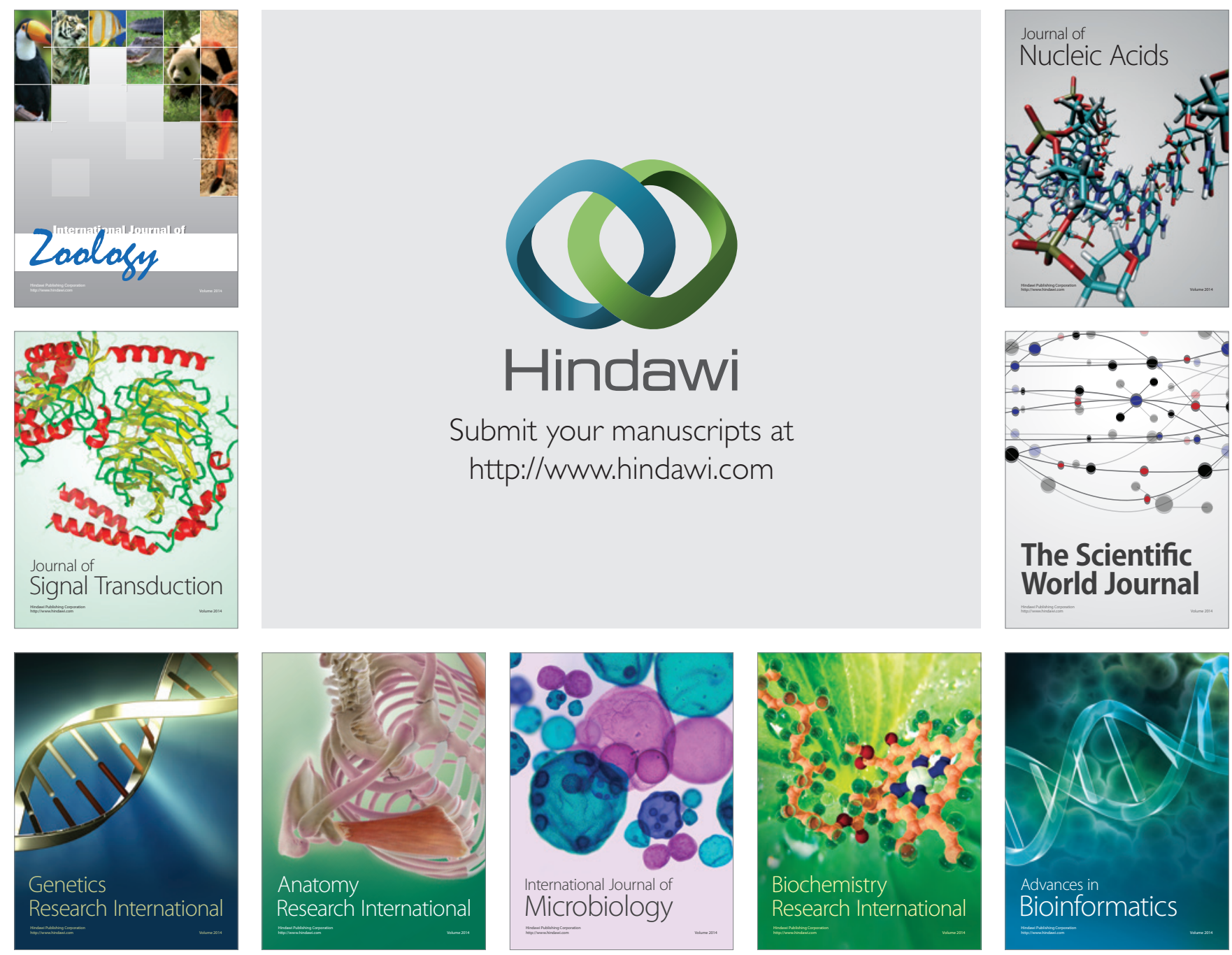

The Scientific World Journal
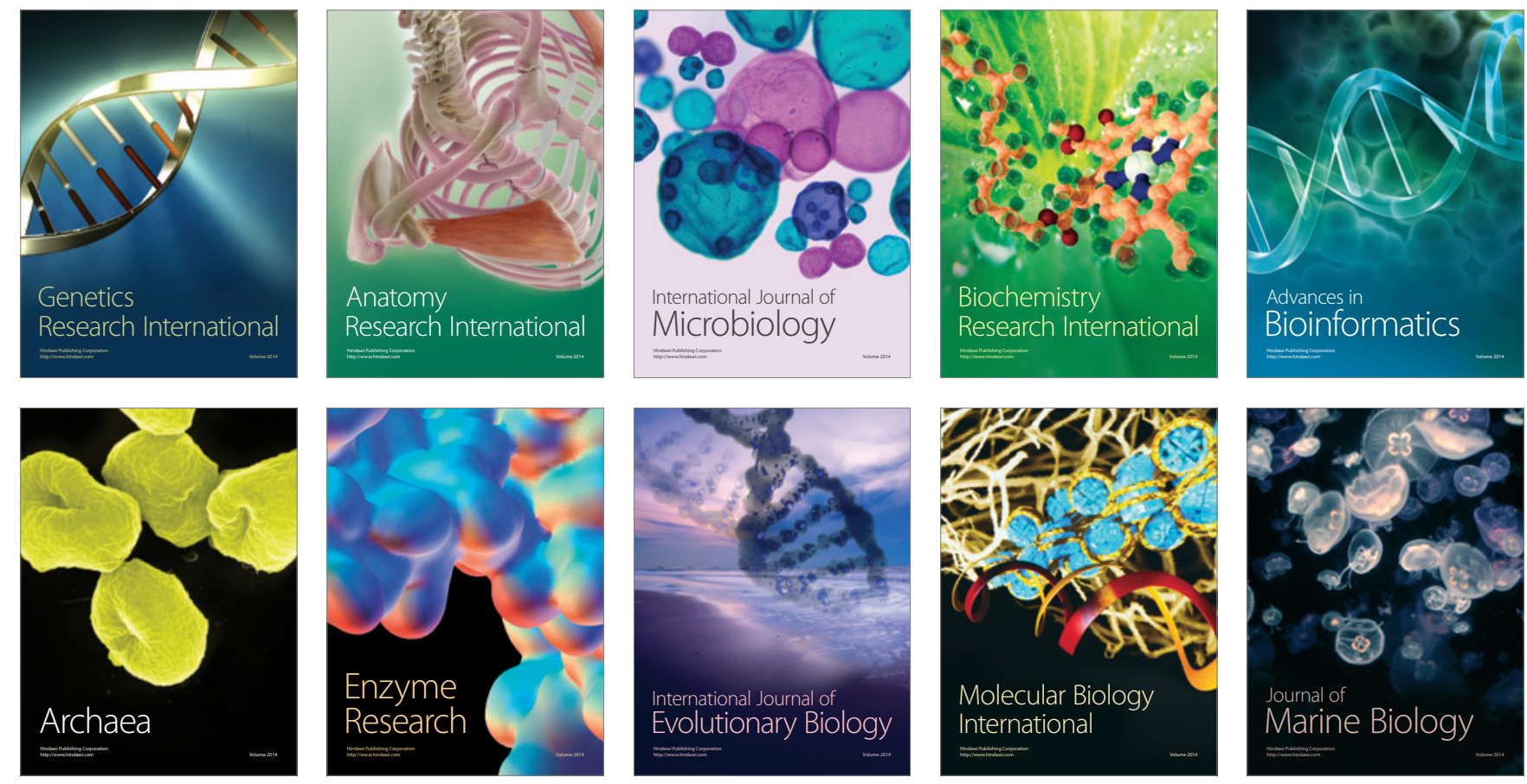